University of Nebraska - Lincoln

DigitalCommons@University of Nebraska - Lincoln

2020

\title{
Nativity and Country of Origin Variations in Life Expectancy With Functional Limitations Among Older Hispanics in the United States
}

\author{
Marc A. Garcia \\ Adriana M. Reyes \\ Catherine García \\ Chi-Tsun Chiu \\ Grecia Macias
}

Follow this and additional works at: https://digitalcommons.unl.edu/sociologyfacpub

Part of the Family, Life Course, and Society Commons, and the Social Psychology and Interaction Commons

This Article is brought to you for free and open access by the Sociology, Department of at DigitalCommons@University of Nebraska - Lincoln. It has been accepted for inclusion in Sociology Department, Faculty Publications by an authorized administrator of DigitalCommons@University of Nebraska - Lincoln. 


\title{
Nativity and Country of Origin Variations in Life Expectancy With Functional Limitations Among Older Hispanics in the United States
}

\author{
Marc A. Garcia, ${ }^{1}$ Adriana M. Reyes, ${ }^{2}$ Catherine García, ${ }^{3}$ \\ Chi-Tsun Chiu, ${ }^{4}$ and Grecia Macias ${ }^{5}$
}

\footnotetext{
1 Department of Sociology and Institute for Ethnic Studies, University of Nebraska-Lincoln, NE, USA

2 Department of Policy Analysis and Management, Cornell University, Ithaca, NY, USA

3 Leonard Davis School of Gerontology, University of Southern California, Los Angeles, CA, USA

4 Institute of European and American Studies, Academia Sinica, Taipei

5 School of Information, University of Michigan-Ann Arbor, MI, USA
Corresponding Author: Marc A. Garcia, Department of Sociology and Institute of Eth- nic Studies, University of Nebraska-Lincoln, 704 Oldfather Hall, Lincoln, NE 68588, USA. Email: marcagarcia@unl.edu
ORCID iD Marc A. Garcia https://orcid.org/0ooo-00o2-9442-4124

\begin{abstract}
This study examined racial/ethnic, nativity, and country of origin differences in life expectancy with and without functional limitations among older adults in the United States. We used data from the National Health Interview Survey (1999-2015) to estimate Sullivan-based life tables of life expectancies with functional limitations and without functional limitations by sex for U.S.-born Mexicans, foreign-born Mexicans, U.S.-born Puerto Ricans, island-born Puerto Ricans, foreign-born Cubans, and U.S.-born Whites. We find that Latinos exhibit heterogeneous life expectancies
\end{abstract}

Published in Research on Aging 2020, Vol. 42(7-8) 199-207

doi:10.1177/0164027520914512

Copyright (c) 2020 Marc A. Garcia, Adriana M. Reyes, Catherine García, Chi-Tsun Chiu, and Grecia Macias. Published by SAGE Publications. Used by permission. 
with functional limitations. Among females, U.S.-born Mexicans, foreign-born Mexicans, and foreign-born Cubans spend significantly fewer years without functional limitations, whereas island-born Puerto Ricans spend more years with functional limitations. For men, U.S.-born Puerto Ricans were the only Latino subgroup disadvantaged in the number of years lived with functional limitations. Conversely, foreign-born Cubans spend significantly fewer years without functional limitations. To address disparities in functional limitations, we must consider variation in health among Latino subgroups.

Keywords: Latinos, race/ethnic disparities, functional limitations, life expectancy

National health expenditures have increased rapidly from 1.4 trillion dollars in 2000 to 3.3 trillion dollars in 2016 with a majority of spending on older adults (Centers for Medicare Medicaid Services, 2018). Among older adults, functional limitations and disability are important health dimensions for researchers to consider, given the strong associations with independent living, declines in quality of life, and rising medical care spending. For instance, high-need, high-cost patients in the United States are individuals who not only have chronic conditions but have chronic conditions that cause a functional limitation (Hayes et al., 2016). These patients have annual health care expenditures that are approximately 3 times higher than individuals with chronic conditions alone. Thus, the high need and care costs of older adults with functional limitations makes it important to understand population heterogeneity in the risk of functional limitations to better target policies and outreach aimed at vulnerable populations.

Previous research has documented functional limitation disparities by race/ethnicity and nativity, finding higher levels of functional limitations for U.S.-born Latinos compared to non- Latino Whites (hereafter Whites) but lower levels of functional limitations for foreignborn Latinos compared to Whites (Cantu et al., 2013; Dallo et al., 2015; Kail et al., 2018). Beyond nativity differentials, prior research has documented large differences in age-specific functional limitations by country of origin among Latinos, demonstrating the need to further examine the demographic heterogeneity among Latino subgroups when assessing health inequality (Melvin et al., 2014).

However, differences in the prevalence of functional limitations by age only partially account for a proportion of the equation that contributes to health disparities, as they do not take into account the amount of years lived with a limitation or differences in longevity 
among population subgroups. Failure to consider how each additional year of life with functional limitations both increases lifetime health care spending and caregiver burden may result in an oversimplified and perhaps misleading depiction of health disparities across the life course. Therefore, it is important for scholars to consider life-course context associated with population variability to better capture the multifaceted nature of health across the life span.

One way to put functional limitations into a life-course context is to combine information on functional limitations with mortality. Mortality differences across race/ethnicity, nativity, and country of origin are well-documented. Older Latinos have been shown to exhibit a lower risk of mortality than Whites, particularly the foreign-born (Fenelon et al., 2017). However, recent findings highlight significant heterogeneity by nativity and country of origin in biological risk profiles (C. Garcia \& Ailshire, 2019), chronic conditions such as diabetes and hypertension (C. Garcia, M. A. Garcia \& Ailshire, 2018), and risk of mortality (Fenelon et al., 2017). Although Latinos, particularly the foreign-born, have longer life expectancies than Whites (M. A. Garcia, C. Garcia, Chiu, Raji \& Markides, 2018; M. A. Garcia, Downer, Chiu, Saenz, Rote, \& Wong, 2019), the individual and social benefits of additional years of life may be undermined if increased longevity is characterized by a high prevalence of functional limitations and dependence.

\section{Background}

Functional limitations are an important indicator of population health, which reflect restrictions in performing fundamental physical actions used in daily life, such as walking, lifting, balancing, and

grasping (Freedman \& Martin, 1998). Functional limitations are also a key part of the disablement process as they precede disability and are sensitive to external factors such as medical care (Verbrugge \& Jette, 1994). These physical limitations then progress into increased difficulty in performing personal care activities such as bathing, dressing, and eating (e.g., activities of daily living) and the difficulty or inability to perform more complicated tasks associated with independent living in the community, such as doing household chores, managing money, and shopping (e.g., instrumental activities of daily living; Martin et al., 2010). Limitations in physical functioning not only act as a 
precursor for various outcomes including, disability, hospitalization, institutionalization, and death, but also correspond with increasing medical care costs (Hayes et al., 2016). Functional limitations become disabilities when individuals have a loss or reduction in the ability to perform activities that affect their expected social roles (Crimmins, 2004; Verbrugge \& Jette, 1994). Although this pathway may not be linear for all individuals, it is generally a process that starts with pathology (e.g., diagnosis of disease), which then progresses into functional limitations and then leads to disability (Crimmins, 2004; Verbrugge \& Jette, 1994).

Although research shows older Latinos enjoy better mortality outcomes than Whites, not all Latino subgroups enjoy better health in late life. For instance, Cantu and colleagues (2013) document that older U.S.-born Latinos live more years with a functional limitation than foreign-born Latinos and Whites, which is indicative of their disadvantaged minority status in the United States. In addition, research documents heterogeneity in the age-specific prevalence of functional limitations among older Latino subgroups. Overall, foreign-born $\mathrm{Cu}$ bans are advantaged in the age-specific prevalence of functional limitations relative to Whites, whereas island-born and U.S.-born Puerto Ricans are disadvantaged relative to Whites (Melvin et al., 2014). Conversely, the Mexican-origin population exhibits large variation in the prevalence of functional limitations by nativity status and age category (Melvin et al., 2014).

Recent evidence highlights the association between nativity status, country of origin, and morbidity life expectancies (i.e., the number and ratio of years lived with cancer, diabetes, heart disease, and stroke) among Latino subgroups (Garcia et al, 2018). These findings show that U.S.-born Puerto Rican men and island-born Puerto Rican women spent a larger proportion of their remaining years after age 50 with morbidity compared to other Latino subgroups. Furthermore, this study documented foreign-born Cuban men and women spent the lowest proportion of late life without morbidity relative to other Latino subgroups (Garcia et al., 2018). Although the above findings demonstrate population variability in morbidity life expectancies among older Latinos, it remains unclear whether nativity status and country of origin are associated with differentials in life expectancy with and without functional limitations. 
Thus, we examine racial/ethnic, nativity, and country of origin differences in life expectancy with and without functional limitations to assess the heterogeneity in quality of life among older Latino men and women. Healthy life expectancy may more accurately capture multiple dimensions of health simultaneously by combining information on mortality and functional limitations into a single indicator. The number of years living with a functional limitation in old age provides information on the number of years with diminished quality of life and increased health care spending.

\section{Research Design}

We analyzed data from the National Health Interview Survey (NHIS), an annual household interview survey of the noninstitutionalized civilian population of the United States, excluding its territories, conducted by the National Center for Health Statistics. Data were pooled across survey years (1999-2015) to obtain a sufficient sample of Latino subgroups by nativity and country of origin. We used the NHIS Linked Mortality Files (NHIS-LMF) to obtain mortality information for respondents. The NHIS-LMF provides mortality followup from the National Death Index (NDI) through December 31, 2015. We restricted our sample to self-identified White and Latino respondents aged 50 to 85 who reported information on nativity, country of origin, and functional limitations. Respondents aged 85 and older are top coded in the NHIS in order to protect the confidentiality among the oldest adults, which constitutes $5.6 \%$ of older adults in the final sample. However, for mortality, age is not top coded in order not to bias our estimates. The final analytic sample included 163,856 unique individuals that contribute 1,423,712 person-years.

\section{Measures}

Functional limitations. Following previous research (Cantu et al., 2013), we focused on the occurrence of at least one of nine selfreported functional limitations: the inability to carry 10 pounds, grasp objects, reach overhead, push large objects, stoop/bend/ kneel, walk three blocks, climb up 10 steps, sit for $2 \mathrm{hr}$, and stand for $2 \mathrm{hr}$. 
Respondents who answered "very difficult" or "cannot do at all" to one or more of these measures were considered to have a functional limitation. Consistent with Cantu and colleagues, we excluded respondents who reported affirmative to "any health problem that requires you to use special equipment."

Sociodemographic characteristics. Nativity and country of origin were combined to classify the three largest Latino subgroups living in the United States into the following groups: U.S.-born Mexicans, foreign-born Mexicans, U.S.-born Puerto Ricans, island-born Puerto Ricans, and foreign-born Cubans. U.S.-born Cubans, Dominicans, and Central/South Americans were omitted due to small cell sizes. U.S.born Whites served as the reference group in the primary analysis, whereas foreign-born Mexicans serve as the reference category in analysis restricted to Latino subgroups. Additional sociodemographic measures assessed included sex and age.

In order to contextualize the sample and differences across population subgroups, we provided summary statistics for the following characteristics: age, years of education, poverty (below federal poverty thresholds), language of interview (Spanish or English), duration in the United States (less than 15 years), ever/current smoker, and any functional limitation.

\section{Analytic Strategy}

In the descriptive analysis, we provided an overview of sociodemographic characteristics by race/ethnicity, nativity, country of origin, and sex. $\mathrm{X}^{2}$ tests for continuous variables and w2 tests for categorical variables were used to compare differences across groups. Statistical significance was assessed at $\alpha=.05$. Although these measures were not included in our life expectancy analyses, we included them to highlight sociocultural variability that has been shown to contribute to functional limitations and mortality differentials among older Latino subgroups by nativity, country of origin, and sex (Cantu et al., 2013; Fenelon et al., 2017; M. A. Garcia \& Reyes, 2018a, 2018b; Zsembik \& Fennell, 2005). For the descriptive analyses, we account for the complex survey design of the NHIS by using Stata's svy commands, which adjusts for population stratification, primary sampling unit, and sample weights. 
We combined age-specific prevalence of functional limitations from the NHIS with age-specific mortality rates from the NHIS-LMF to calculate Sullivan life table models of life expectancy with and without functional limitations, for each race/ethnic, nativity, and country of origin group by sex (Sullivan, 1971). This is a prevalence-based method of estimating healthy life expectancy which divides total life expectancy into healthy (without functional limitations) and unhealthy (with functional limitations) states based on the age-specific prevalence without functional limitations and the age-specific prevalence with functional limitations. Physical functioning life expectancies calculated by this method are the average number of years (at age 50) a population can expect to live with a functional limitation and without a functional limitation (Jagger et al., 2014). The prevalence of functional limitations by age and sex is estimated with logistic regression for each race/ ethnic, nativity, and country of origin group with sampling weights provided by NHIS. To estimate mortality, we used Gompertz hazard models with sampling weights provided by NHIS-LMF. A weighted bootstrapping technique was used to obtain standard errors for total life expectancy, life expectancy with functional limitations, and life expectancy without functional limitations (Efron \& Tibshirani, 1986). Bootstrapping generates repeated estimates of life expectancy by randomly drawing a series of bootstrap samples from the analytic samples. Based on 300 bootstrap samples for each group, 95\% empirical intervals were obtained from the $2.5^{\text {th }}$ to the $97.5^{\text {th }}$ percentile of the distributions of total life expectancy, life expectancy with functional limitations, and life expectancy without functional limitations for each group by sex, which allow us to estimate sampling variability in different states. Further information on computing the Sullivan method is available elsewhere (Jagger et al., 2014; Saito et al., 2014).

\section{Results}

\section{Descriptive Statistics}

Key characteristics are presented in Table 1 by race/ethnicity, nativity, country of origin, and sex to demonstrate variability in sociodemographic, immigrant adaptation, and health characteristics. Among the Latino subgroups in the analysis, foreign-born Mexicans comprised 
Table 1. Sample Characteristics by Race/Ethnicity, Nativity, Country of Origin, and Sex.

\begin{tabular}{|c|c|c|c|c|c|c|}
\hline Variables & U.S. White & U.S Mexican & FB Mexican & U.S. Puerto Rican & IB Puerto Rican & FB Cuban \\
\hline \multicolumn{7}{|l|}{ Panel A: Females } \\
\hline Age $(\boldsymbol{S D})^{\mathrm{a}}$ & $66.3(10.9)$ & $63.8(10.2)$ & $62.1(9.5)$ & $58.3(8.1)$ & $64.9(9.6)$ & $67.8(10.2)$ \\
\hline Education $(\boldsymbol{S D})^{\mathrm{a}}$ & $13.5(3.3)$ & $11.8(6.1) 8$ & $.2(5.6)$ & $13.2(2.5)$ & $10.9(5.5)$ & $11.6(3.9)$ \\
\hline Below poverty ${ }^{a}$ & 9.5 & 20.3 & 32.8 & 20.9 & 37.5 & 28.3 \\
\hline Spanish interviewa & - & 10.8 & 68.3 & 10.6 & 40.0 & 75.2 \\
\hline Duration: Less than 15 years ${ }^{a}$ & - & - & 13.6 & - & 9.1 & 16.8 \\
\hline Smoking: Current/evera & 44.9 & 32.1 & 19.2 & 47.0 & 28.4 & 24.4 \\
\hline Any functional limitation ${ }^{a}$ & 35.6 & 38.4 & 33.6 & 36.3 & 46.6 & 29.9 \\
\hline \multicolumn{7}{|l|}{$\begin{array}{l}\text { Any functional limitation } \\
\text { by Age Category: }\end{array}$} \\
\hline $50-59^{a}$ & 23.0 & 28.3 & 22.8 & 34.7 & 41.5 & 13.7 \\
\hline $60-69^{a}$ & 31.0 & 40.3 & 36.4 & 44.1 & 46.8 & 23.3 \\
\hline $70-79^{a}$ & 42.6 & 47.8 & 50.6 & 35.7 & 54.4 & 35.0 \\
\hline $80+a$ & 63.8 & 69.5 & 71.8 & 80.0 & 66.4 & 56.6 \\
\hline $\mathbf{N}$ & 81,980 & 3,732 & 3,510 & 376 & 1,395 & 1,316 \\
\hline \multicolumn{7}{|l|}{ Panel B: Males } \\
\hline Age $(\boldsymbol{S D})^{\mathrm{a}}$ & $64.1(10.1)$ & $62.8(9.5)$ & $60.8(9.0)$ & $58.3(7.9)$ & $64.5(9.5)$ & $66.6(10.3)$ \\
\hline Education (SD) a & $13.6(3.2)$ & $12.3(4.2)$ & $8.1(5.6)$ & $13.4(2.5)$ & $11.0(4.1)$ & $12.0(5.3)$ \\
\hline Below poverty ${ }^{a}$ & 7.0 & 14.0 & 26.1 & 18.3 & 26.8 & 23.8 \\
\hline Spanish interview ${ }^{\mathrm{a}}$ & - & 7.9 & 65.4 & 8.9 & 30.7 & 68.8 \\
\hline Duration: Less than 15 years ${ }^{a}$ & - & - & 12.5 & - & 6.3 & 15.6 \\
\hline Smoking: Current/ever ${ }^{a}$ & 62.0 & 59.3 & 48.2 & 62.0 & 55.5 & 50.0 \\
\hline Any functional limitation ${ }^{a}$ & 24.0 & 25.6 & 20.3 & 23.0 & 30.3 & 21.5 \\
\hline \multicolumn{7}{|l|}{$\begin{array}{l}\text { Any functional limitation } \\
\text { by Age Category: }\end{array}$} \\
\hline $50-59^{a}$ & 16.1 & 21.3 & 11.5 & 22.7 & 25.4 & 12.2 \\
\hline $60-69^{a}$ & 22.7 & 26.8 & 22.7 & 17.9 & 29.7 & 17.9 \\
\hline $70-79 a$ & 30.0 & 33.3 & 38.0 & 33.3 & 32.6 & 20.2 \\
\hline $80+{ }^{a}$ & 48.6 & 57.7 & 68.7 & 57.1 & 58.3 & 42.5 \\
\hline$N$ & 63,600 & 2,743 & 3,004 & 306 & 907 & 987 \\
\hline
\end{tabular}

Source: National Health Interview Survey 1999-2015.

Note. Unweighted $\mathbf{N s}$; weighted means and percentages; FB = foreign-born; IB = island-born.

asignificantly different across groups at $\boldsymbol{p}<.05$.

$36 \%$ of the sample. U.S.- born Mexicans were the next largest (35\%), followed by island-born Puerto Ricans (13\%), foreign-born Cubans (12\%), and U.S.-born Puerto Ricans (4\%).

Among both males and females, foreign-born Cubans were the oldest, while U.S.-born Puerto Ricans were the youngest Latino subgroup. Foreign-born Mexicans, regardless of sex, were the least educated. Poverty was higher among all Latino subgroups compared to Whites, with females exhibiting the highest poverty levels, especially those born outside of the United States. Overall, a clear sociodemographic 
advantage was evident for Whites and to a lesser extent for those born in the United States as opposed to those born in Mexico, Puerto Rico, and Cuba.

Two important markers of immigrant adaptation are language of interview and duration in the United States. Within each country of origin group, females were more likely to take the survey in Spanish. More than $65 \%$ of those born in Cuba and Mexico took the survey in Spanish whereas less than $40 \%$ of other groups took the survey in Spanish. Among those who immigrated to the United States, females from Cuba have the largest share of recent (less than 15 years) immigrants (17\%), then males from Cuba (16\%), followed by Mexicans (14\% females; $13 \%$ males), and lastly island-born Puerto Ricans (9\% females; 6\% males). Foreign-born Cubans and Mexicans were both more likely to be recent immigrants and more likely to take the survey in Spanish, suggesting a lower level of adaptation to the United States for these groups.

Among women, large variations in smoking were reported across nativity and country of origin. U.S.-born Puerto Rican women reported the highest levels of smoking (47\%), while foreign-born Mexican women reported the lowest levels (19\%). Similar patterns in smoking were observed among Latino males. Moreover, all Latino subgroups (apart from U.S.-born Puerto Ricans) reported lower rates of smoking than Whites. Island born Puerto Rican women and men reported the highest prevalence of functional limitations (47\%and 30\%, respectively) compared to other population subgroups. However, our results exhibited substantial variation by nativity, country of origin, and sex in the age-specific prevalence of functional limitations.

For female adults aged 50-59, all immigrant groups, except for island-born Puerto Ricans, exhibited a lower prevalence of functional limitations in comparison to Whites. This pattern reverses at age 80, with all immigrant groups exhibiting a higher prevalence of functional limitations compared to Whites. Within Latino females, island-born Puerto Ricans reported a higher prevalence of functional limitations at ages 50-59, 6o-69, and 70-79 relative to other Latino subgroups, whereas foreign-born Cubans reported the lowest prevalence of functional limitations among Latino subgroups. However, at ages 80-85, the prevalence of functional limitations among U.S.-born Puerto Ricans, U.S.-born Mexicans, and foreign-born Mexicans converges to that of island-born Puerto Ricans. 
Among men, aged 50-59, foreign-born Mexican and foreign-born Cubans exhibited a lower prevalence of functional limitations than Whites. Although the pattern among foreign born Mexicans reverses at ages 6o-69, foreign-born Mexicans report a higher prevalence of functional limitations than Whites. Conversely, foreign-born Cubans remain advantaged at older ages in the prevalence of functional limitations compared to Whites. Within Latino males, island-born Puerto Ricans exhibited a higher prevalence of functional limitations at ages 50-59 and 6o-69 compared to the other Latino subgroups, whereas foreign-born Mexicans exhibited a higher prevalence at ages 70-79 and $80-85$.

\section{Life Expectancy With and Without Functional Limitations}

Table 2 presents life expectancy with and without functional limitations at age 50 for men and women by race/ethnicity, nativity, and country of origin. Overall, females had longer total life expectancies than their male counterparts and spend a smaller proportion of their remaining years without functional limitations.

Among women (Panel A), we found that older Latino subgroups were heterogeneous in life expectancy with and without functional limitations (see Figure 1). At age 50, U.S.-born Mexicans, foreign-born Mexicans, and island-born Puerto Ricans spend significantly fewer years without functional limitations than Whites (19.0 years, 18.6 years, and 17.8 years vs. 20.9 years), whereas foreign-born Cuban women spend more years without functional limitations (25.0 years) compared to Whites (20.9 years). Furthermore, U.S.-born Mexicans, foreign-born Mexicans, and island-born Puerto Ricans spend significantly more years with functional limitations than Whites (15.3 years, 16.7 years, and 18.4 years vs. 13.2 years), indicating these women spend a lesser share of their life after age 50 without functional limitations (55\%, 53\%, and 49\% vs. 61\%). In contrast, foreign-born $\mathrm{Cu}$ ban women spend significantly fewer years with a functional limitation (11.3 years) and a larger proportion of late life without functional limitations (69\%) compared to White women. 
Table 2. Functional Limitation Life Expectancies at Age 50 by Race/Ethnicity, Nativity, Country of Origin, and Sex.

\begin{tabular}{|c|c|c|c|c|c|c|c|c|c|c|c|c|}
\hline \multirow[b]{2}{*}{ Outcome } & \multicolumn{2}{|c|}{$\begin{array}{l}\text { U.S. } \\
\text { White }\end{array}$} & \multicolumn{2}{|c|}{$\begin{array}{c}\text { U.S. } \\
\text { Mexican }\end{array}$} & \multicolumn{2}{|c|}{$\begin{array}{c}\text { FB } \\
\text { Mexican }\end{array}$} & \multicolumn{2}{|c|}{$\begin{array}{c}\text { U.S. } \\
\text { Puerto Rican }\end{array}$} & \multicolumn{2}{|c|}{$\begin{array}{c}\text { IB } \\
\text { Puerto Rican }\end{array}$} & \multicolumn{2}{|c|}{$\begin{array}{l}\text { FB } \\
\text { Cuban }\end{array}$} \\
\hline & Years & $\mathrm{El}$ & Years & $\mathrm{El}$ & Years & $\mathrm{El}$ & Years & $\mathrm{EI}$ & Years & $\mathrm{El}$ & Years & $\mathrm{El}$ \\
\hline \multicolumn{13}{|l|}{ Panel A: Females } \\
\hline Total life expectancy & 34.1 & 0.07 & 34.3 & 0.30 & 35.3 & $0.50^{\mathrm{a}}$ & 36.4 & 2.16 & 36.3 & $0.80^{\mathrm{a}}$ & 36.3 & $0.44^{a}$ \\
\hline LE without functional limitations & 20.9 & 0.06 & 19.0 & $0.55^{\mathrm{a}}$ & 18.6 & $0.37^{\mathrm{a}}$ & 19.7 & 1.88 & 17.8 & $0.81^{\mathrm{a}}$ & 25.0 & $0.50^{\mathrm{a}, \mathrm{b}}$ \\
\hline LE with functional limitations & 13.2 & 0.07 & 15.3 & $0.36^{a, b}$ & 16.7 & $0.52^{\mathrm{a}}$ & 16.7 & 2.20 & 18.4 & $0.81^{\mathrm{a}}$ & 11.3 & $0.51^{\mathrm{a}, \mathrm{b}}$ \\
\hline Ratio LE without functional limitations & 0.61 & 0.01 & 0.55 & $0.01^{\mathrm{a}}$ & 0.53 & $0.01^{\mathrm{a}}$ & 0.54 & 0.05 & 0.49 & $0.02^{\mathrm{a}}$ & 0.69 & $0.01^{a, b}$ \\
\hline \multicolumn{13}{|l|}{ Panel B: Males } \\
\hline Total life expectancy & 30.4 & 0.06 & 29.8 & $0.33^{b}$ & 32.7 & $0.54^{\mathrm{a}}$ & 34.2 & $2.60^{\mathrm{a}}$ & 30.0 & $0.63^{b}$ & 30.7 & $0.48^{b}$ \\
\hline LE without functional limitations & 22.3 & 0.07 & 20.9 & $0.38^{a}$ & 21.4 & 0.45 & 24.5 & 2.46 & 19.9 & $0.60^{a, b}$ & 24.1 & $0.50^{a, b}$ \\
\hline LE with functional limitations & 8.1 & 0.06 & 9.0 & $0.34^{a, b}$ & 11.3 & $0.53^{\mathrm{a}}$ & 9.7 & 2.33 & 10.1 & $0.60^{\mathrm{a}}$ & 6.6 & $0.44^{a, b}$ \\
\hline Ratio LE without functional limitations & 0.73 & 0.01 & 0.70 & $0.01^{a, b}$ & 0.65 & $0.01^{\mathrm{a}}$ & 0.72 & 0.06 & 0.66 & $0.02^{a}$ & 0.78 & $0.01^{a, b}$ \\
\hline
\end{tabular}

Source: National Health Interview Survey 1999-2015.

$\mathrm{LE}=$ life expectancy. $\mathrm{EI}=$ empirical interval. $\mathrm{FB}=$ foreign-born. $\mathrm{IB}=$ island-born.

a. Indicates differences from U.S. Whites $(\boldsymbol{p}<.05)$.

b. Indicates differences from FB Mexicans $(\boldsymbol{p}<.05)$.

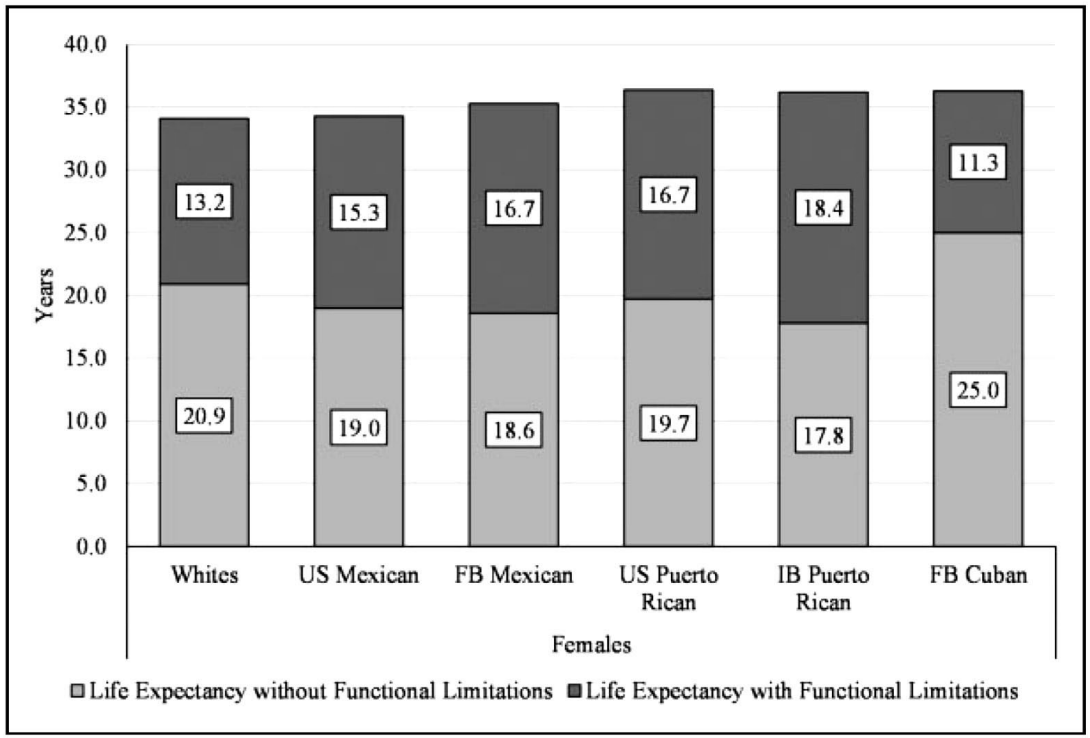

Figure 1. Estimated years of life expectancy at age 50 with and without functional limitations by race/ethnicity, nativity, and country of origin among females. Source: National Health Interview Survey 1999-2015. 


\section{Latino Subgroup Variability}

In general, island-born Puerto Rican women were the most disadvantaged and foreign-born Cuban women the most advantaged among Latino subgroups both in the total years with and without a functional limitation and the proportion of late life lived without a physical functioning limitation than Whites.

Among men (Panel B), results indicate at age 50, U.S.-born Mexicans and island-born Puerto Ricans (20.9 years and 19.9 years) spend significantly fewer years without functional limitations than Whites (22.3 years), whereas foreign-born Cuban men spend significantly more years (24.1 years) without functional limitations than Whites.

In addition, U.S.-born Mexicans, foreign-born Mexicans, and island-born Puerto Ricans spend significantly more years with functional limitations than Whites (9.0 years, 11.3 years, and 10.1 years vs. 8.1 years), and foreign-born Cuban spend significantly fewer years (6.6 years) with functional limitations compared to Whites (see Figure 2). In contrast, U.S.-born Puerto Ricans did not differ from Whites in the number of years after age 50 with functional limitations. Similar to women, foreign-born Cuban men spend the largest proportion

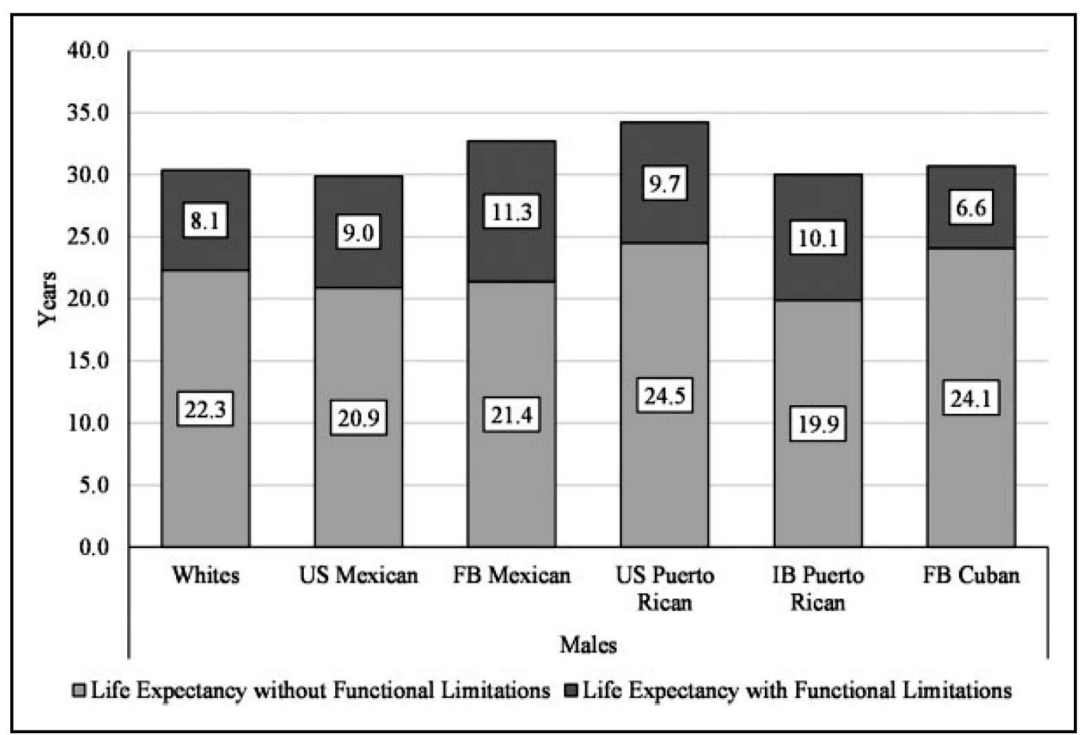

Figure 2. Estimated years of life expectancy at age 50 with and without functional limitations by race/ethnicity, nativity, and country of origin among males. Source: National Health Interview Survey 1999-2015. 
of their remaining late life years without a functional limitation relative to Whites (78\% vs. $73 \%$ ). In contrast, foreign-born Mexican men are the most disadvantaged in the proportion of late life spent with functional limitations (65\%) compared to White men. Within Latino subgroups, island-born Puerto Rican men were significantly disadvantaged in the number of years without a functional limitation compared to foreign-born Mexicans, and foreign-born Cuban men were significantly advantaged in the number of years without a functional limitation relative to foreign-born Mexicans. In addition, U.S.-born Mexican and foreign-born Cuban men spend significantly fewer years with a functional limitation compared to foreign-born Mexican men and a significantly larger proportion of their late life without a functional limitation.

\section{Discussion}

We build on previous research assessing racial/ethnic and nativity disparities in life expectancy with and without functional limitations in the United States by using nationally representative data to examine variability among Latino subgroups aged 50 and older. We speculated that life expectancy with and without functional limitations would vary considerably among older Latinos by nativity and country of origin, given large differences in sociocultural characteristics that shape the life course of Latino subgroups and lead to diverging health patterns in old age (Melvin et al., 2014). We found that for women, combining all Latino subgroups masks an almost 6-year difference in the average number of years with a functional limitation between the least healthy group, island born Puerto Ricans, and the healthiest subgroup, foreign-born Cubans. Among men, the subgroup heterogeneity is smaller than for women, but significant differences exist with a 4-year difference in years with a functional limitation between foreign-born Cuban men (the healthiest) and U.S.-born Puerto Ricans (least healthy).

The healthy immigrant effect documented in previous literature is evident among men and women (Fenelon et al., 2017). Among women, the three longest living groups are foreign born Mexicans, foreignborn Cubans, and island-born Puerto Ricans. Foreign-born Mexican 
men and foreign-born Cuban men also exhibit a life expectancy advantage relative to Whites. Island-born Puerto Rican men do not have a life expectancy advantage relative to White men, however since Puerto Ricans are U.S. citizens, they may be less selected on health.

Living longer does not coincide with living healthier for some Latino subgroups. For instance, Puerto Rican women despite having relatively long-life expectancies spend the greatest number of years with functional limitations. In contrast, foreign-born Mexican and Cuban women live the fewest years with functional limitations. These results are consistent with previous findings on prevalence of functional limitations for respondents aged 50-64 that show foreign-born Mexican and foreign-born Cuban women are less likely to have a functional limitation than Whites (Melvin et al., 2014). The limited health selection of island-born Puerto Ricans may help explain why this group spends more years with functional limitations than other foreign-born groups. However, understanding why island-born Puerto Rican women have the longest life expectancy of all groups and spend the greatest share of years with functional limitations is more complicated.

Both individual characteristics and structural processes are related to the pace of the disablement process (Verbrugge \& Jette, 1994). In the case of the island-born Puerto Ricans, their high burden of disease (C. Garcia, M. A. Garcia \& Ailshire, 2018; Garcia et al., 2018), high levels of poverty, and low levels of education may speed the disablement process, such that functional limitations occur relatively early in the life course. Indeed, island-born Puerto Rican women have the highest rate of functional limitations at ages 50-59, but not for older age groups. Access to medical care can also change the speed of the disablement process, so access to medical care through Medicare at age 65 may come too late to stem functional limitations for island-born Puerto Rican women but early enough to prevent mortality. As some groups start the disablement process at younger ages, access to universal health care may come too late in the life course for these groups.

Although we do find population variability by Latino subgroup, for both men and women, much of the difference in life expectancy with and without functional limitations is concentrated among the foreignborn, with Mexicans and Cubans having longer and healthier lives than Whites and other U.S.- born Latino subgroups. This finding supports previous research that finds better health among foreign-born 
Latinos for many health outcomes (Cantu et al., 2013; Hummer et al., 2013; Melvin et al., 2014) and suggests that health selection may help explain part of the results. However, this does not apply to island-born Puerto Ricans who are not immigrants but rather U.S. citizens by birth and therefore likely less health selected.

Among men, U.S.-born Mexicans and foreign-born Cubans exhibit an advantage in life expectancies with and without functional limitations relative to Whites. Foreign-born Mexicans and U.S.-born Puerto Ricans also spend more years living without a functional limitation than Whites; however, U.S.- born Puerto Ricans spend more years with functional limitations than Whites.

Consistent with previous research we observe longer life expectancies for Latino subgroups with lower smoking rates, with the exception of U.S.-born Puerto Rican men who have the longest life expectancy among men yet report the highest level of smoking prevalence (Fenelon, 2013; Lariscy et al., 2015). However, rates of smoking by Latino subgroup are not predictive of life expectancy with functional limitations. Island-born Puerto Rican women exhibit low levels of smoking yet spend a large share of years with functional limitations. Foreignborn Mexican men exhibit the lowest rate of smoking for men yet are disadvantaged with regard to share of years with functional limitations. Although we know smoking is detrimental for health, it does not appear to explain subgroup differences in life expectancies with functional limitations.

U.S.-born Puerto Rican men have the longest total life expectancy among men yet they spend the greatest number of years with functional limitations. Previous research has found U.S.-born Puerto Ricans to have worse health across a variety of measures (Hajat et al., 2000; Torres-Pag'an, 2016). Their longer life expectancy despite more years with functional limitations suggests they are better able to delay the progression of the disablement process and eventually death. U.S.-born Puerto Rican men have high levels of education, which may allow them to buffer and delay death. These worse health outcomes despite better education may stem from higher rates of smoking as well as the cumulative effects of stress from a lifetime experiencing racial discrimination in employment and housing markets (Burgos \& Rivera, 2012). Foreign-born Cuban men live the fewest years with functional limitations, which may be attributed to the high education and wealth levels of the initial Cuban immigrants fleeing during the 
Cuban revolution (Eckstein, 2006; Keister \& Aronson, 2017). Although our analyses do not directly test these mechanisms, drawing on previous research, we speculate on some of the potential mechanisms to understand observed differences in life expectancies with and without functional limitations.

Overall, these results demonstrate that late life health outcomes are not uniform across older Latino subgroups. Island born Puerto Rican women, on average, spend more than 15 years coping with functional limitations, whereas Whites spend only 12 years and foreign-born $\mathrm{Cu}$ bans less than 10 years. Men on average have shorter life expectancies and spend fewer years with functional limitations than women. Among men, U.S.-born Puerto Ricans spend the most years with functional limitations (10 years) and foreign-born Cubans spend the fewest ( 6 years). These results highlight the importance of disaggregating Latinos by country of origin and nativity.

\section{Limitations}

Despite this study's strengths in documenting heterogeneity in life expectancy with and without functional limitations within the Latino population, our study has several limitations. First, this analysis pooled 17 years of data to obtain a large number of Latino subgroups. Although using a pooled sample has the benefit of increasing the reliability and precision of estimates, we make an assumption that population characteristics are stable across survey years.

Second, we used linked NHIS-LMF records to obtain mortality information that relies in part on social security numbers which may lead to undocumented Latinos' deaths being unmatched. However, mortality matches for Latinos using this data have been found to be highly accurate and correspond well with National Vital Statistics (Lariscy, 2011, Lariscy et al., 2015; Brown, Lariscy, \& Kalousova, 2019). Thus, bias from unmatched records is minimal and unlikely to substantially change our findings.

Third, information on physical functioning is based on self-reports. If U.S. older adults changed systematically in how they understand and report physical functioning over time, the life expectancies presented may be biased. Future studies should use alternative data sources that have objective measures of physical functioning to address this potential bias. 
Fourth, prior studies have shown that health differences within the Latino population are related to age patterns of migration, a measure not available in the NHIS (M. A. Garcia \& Reyes 2018a, 2018b; M. A. Garcia et al., 2017). Fifth, our sample of U.S.-born Puerto Rican population is relatively small compared to other subgroups, and as such, our results for the U.S.-born Puerto Rican population should be interpreted with caution. Finally, the NHIS does not include individuals who are institutionalized (e.g., living in nursing homes). Thus, our sample may be healthier than the overall U.S. population, which may underestimate the extent of certain groups living with functional limitations.

\section{Conclusion}

These findings enhance our understanding of variation in functional limitations among Latino subgroups beyond mortality differentials. The results demonstrate the need to look at late life health outcomes and life expectancy simultaneously to better understand late life health inequalities. For both men and women, the national origin group with the longest total life expectancy experienced the greatest proportion of old age with a functional limitation. Although functional limitations as a part of the disablement process precede disability, disparities in disability may be even larger since disabilities have an environmental component that may allow more advantaged groups to delay disability (Verbrugge \& Jette, 1994). Nonetheless, living with functional limitations for a greater share of late life will have real implications for quality of life and spending on health care (Hayes et al., 2016).

The Latino share of the population 65 and older will increase from $8 \%$ to $21 \%$ by 2060 (U.S. Census Bureau, 2018), so public health practitioners and policy makers need to understand the unique risks and health needs of this diverse group of older adults. As rising inequality and differential levels of assimilation among Latinos lead to diverging experiences and outcomes, future research needs to continue to unpack the intragroup differences. Improving access to health care and the cultural competency of providers may help improve the care provided to the groups most at risk.

As a part of the disablement process, years with functional limitations represent risk to further disablement and costly medical care. 
Further, since functional limitations are sensitive to medical care, they represent a key policy indicator of potentially mitigated health inequalities. Additionally, advances in the prevention and treatment of underlying conditions of functional limitations have major implications for the future health of these populations. While substantial progress had been made in treating some conditions such as cancer, there have been far fewer advances in treating many of the underlying conditions for functional limitations. A better understanding of public health interventions and behavioral changes that will improve functional limitations is needed in order to formulate targeted interventions for those most at risk of living for an extended period with functional limitations.

Conflicting Interests - The authors declared no potential conflicts of interest with respect to the research, authorship, and publication of this article.

Funding - Research reported in this publication was supported by the National Institutes of Health (P30 AG059300) and the Nebraska Tobacco Settlement Biomedical Research Development Funds for M. A. Garcia and the National Institute on Aging of the National Institutes of Health under Award Number R36AG057949 for Catherine García.

\section{References}

Brown, D. C., Lariscy, J. T., \& Kalousová, L. (2019). Comparability of mortality estimates from social surveys and vital statistics data in the United States. Population Research and Policy Review, 38(3), 371-401.

Burgos, G., \& Rivera, F. I. (2012). Residential segregation, socioeconomic status, and disability: A multi-level study of Puerto Ricans in the United States. Centro Journal, 24(2), 14-47.

Cantu, P., Hayward, M., Hummer, R., \& Chiu, C.-T. (2013). New estimates of racial/ethnic differences in life expectancy with chronic morbidity and functional loss: Evidence from the National Health Interview Survey. Journal of Cross-Cultural Gerontology, 28(3),

283-297. https://doi.org/10.1007/s10823-013-9206-5

Centers for Medicare Medicaid Services. (2018). National health expenditures 2016 highlights. https://www.cms.gov/Research-Statistics-Data-andSystems/Statistics-Trends-and-Reports/NationalHealthExpendData/

NationalHealthAccountsHistorical

Crimmins, E. M. (2004). Trends in the health of the elderly. Annual Review of Public Health, 25, 79-98. 
Dallo, F. J., Booza, J., \& Nguyen, N. D. (2015). Functional limitations and nativity status among older Arab, Asian, black, Hispanic, and white Americans. Journal of Immigrant and Minority Health, 17(2), 535-542.

Eckstein, S. (2006). Transnational family based social capital: Remittances and the transformation of Cuba. International Journal of Sociology of the Family, 32(2), 141-171.

Efron, B., \& Tibshirani, R. (1986). Bootstrap methods for standard errors, confidence intervals, and other measures of statistical accuracy. Statistical Science, 1, 54-75.

Fenelon, A. (2013). Revisiting the Hispanic paradox in the United States: The role of smoking. Social Science \& Medicine (1982), 82, 1-9. https://doi.org/10.1016/j. socscimed.2012.12.028

Fenelon, A., Chinn, J. J., \& Anderson, R. N. (2017). A comprehensive analysis of the mortality experience of Hispanic subgroups in the United States: Variation by age, country of origin, and nativity. SSM-Population Health, 3, 245-254.

Freedman, V. A., \& Martin, L. G. (1998). Understanding trends in functional limitations among older Americans. American Journal of Public Health, 88(10), 1457-1462.

García, C., \& Ailshire, J. (2019). Biological risk profiles among Latino subgroups in the health and retirement study. Innovation in Aging, 3(2), igzo17. https://doi.org/10.1093/ geroni/igzo17

Garcia, C., Garcia, M. A., \& Ailshire, J. A. (2018). Sociocultural variability in the Latino population: Age patterns and differences in morbidity among older US adults.

Demographic Research, 38(52), 1605-1618.

Garcia, M. A., Downer, B., Chiu, C. T., Saenz, J., Rote, S., \& Wong, R. (2019). Racial/ethnic and nativity differences in cognitive life expectancies among older adults in the United States. The Gerontologist, 59(2), 281-289. https://doi.org/10.1093/geront/gnx142

Garcia, M. A., Garcia, C., Chiu, C. T., Raji, M., \& Markides, K. (2018). A comprehensive analysis of morbidity life expectancies among older Hispanic subgroups in the United States: Variation by nativity and country of origin. Innovation in Aging, 2(2), igyo14. https://doi.org/10.1093/geroni/igy014

Garcia, M. A., \& Reyes, A. M. (2018a). Physical functioning and disability trajectories by age of migration among Mexican elders in the United States. The Journals of Gerontology: Series B, 73(7), 1292-1302. https://doi.org/10.1093/geronb/gbw167

Garcia, M. A., \& Reyes, A. M. (2018b). Prevalence and trends in morbidity and disability among older Mexican Americans in the Southwestern United States, 1993-2013. Research on Aging, 40(4), 311-339. https://doi.org/10.1177/0164027517697800

Garcia, M. A., Valderrama-Hinds, L. M., Chiu, C. T., Mutambudzi, M. S., Chen, N. W., \& Raji, M. (2017). Age of migration life expectancy with functional limitations and morbidity in Mexican Americans. Journal of the American Geriatrics Society, 65(7), 1591-1596. https://doi.org/10.1111/jgs.14875

Hajat, A., Lucas, J. B., \& Kington, R. (2000). Health outcomes among Hispanic subgroups: Data from the National Health Interview Survey, 1992-95. Advance Data, 25(310), 1-14.

Hayes, S. L., Salzberg, C. A., McCarthy, D., Radley, D. C., Abrams, M. K., Shah, T., \& Anderson, G. F. (2016). High-need, high-cost patients: Who are they and how do they use health care. A population-based comparison of demographics, health care use, and expenditures (pp. 1-14) (Issue Brief 26). Commonw Fund. 
Hummer, R. A., Melvin, J. E., Sheehan, C. M., \& Wang, Y.-T. (2013). Race/ethnicity, mortality and longevity. In K. E. Whitfield \& \& T. A. Baker (Eds.), Handbook of minority aging (pp. 131-152). Springer.

Jagger, C., Van Oyen, H., \& Robine, J.-M. (2014). Health expectancy calculation by the Sullivan method: A practical guide. Institute for Ageing, Newcastle University.

Kail, B. L., Taylor, M. G., \& Rogers, N. (2018). Double disadvantage in the process of disablement: Race as a moderator in the association between chronic conditions and functional limitations. The Journals of Gerontology: Series B, 75(2), 448-458.

Keister, L. A., \& Aronson, B. (2017). Immigrants in the one percent: The national origin of top wealth owners. PLoS One, 12(2), e0172876.

Lariscy, J. T. (2011). Differential record linkage by Hispanic ethnicity and age in linked mortality studies: Implications for the epidemiologic paradox. Journal of Aging and Health, 23(8), 1263-1284.

Lariscy, J. T., Hummer, R. A., \& Hayward, M. D. (2015). Hispanic older adult mortality in the United States: New estimates and an assessment of factors shaping the Hispanic paradox. Demography, 52(1), 1-14. https://doi.org/10.1007/s13524-014-0357-y

Martin, L. G., Schoeni, R. F., \& Andreski, P. M. (2010). Trends in health of older adults in the United States: Past, present, future. Demography, 47(Suppl. 1), S17-S40.

Melvin, J., Hummer, R., Elo, I., \& Mehta, N. (2014). Age patterns of racial/ethnic/nativity differences in disability and physical functioning in the United States. Demographic Research, 31, 497-509.

Saito, Y., Robine, J.-M., \& Crimmins, E. M. (2014). The methods and materials of health expectancy. Statistical Journal of the IAOS, 3O(3), 209-223.

Sullivan, D. F. (1971). A single index of mortality and morbidity. HSMHA Health Reports, 86(4), 347-354.

Torres-Pagán, L. (2016). Health of Puerto Ricans in United States 2010-2015. Centro de Estudios Puertorriquen os.

U.S. Census Bureau, Population Division. (2018). Race and Hispanic origin by selected age groups: Main projections series for the United States, 2017-2060. https://www.census. gov/data/tables/2017/demo/popproj/2017-summary-tables.html

Verbrugge, L. M., \& Jette, A. M. (1994). The disablement process. Social Science \& Medicine, 38(1), 1-14.

Zsembik, B. A., \& Fennell, D. (2005). Ethnic variation in health and the determinants of health among Latinos. Social Science \& Medicine, 61(1), 53-63. 


\section{Author Biographies}

Marc A. Garcia is an assistant professor in the Department of Sociology and Institute for Ethnic Studies at the University of Nebraska- Lincoln. His research centers broadly on the physical and cognitive health of minority and immigrant populations.

Adriana M. Reyes is an assistant professor in the Department of Policy Analysis and Management at Cornell University. Her research focuses on health disparities across the life course and intergenerational relationships.

Catherine García is a doctoral candidate at the Leonard Davis School of Gerontology at the University of Southern California.

Chi-Tsun Chiu is an assistant research fellow at the Institute of European and American Studies, Academia Sinica. His research focuses on healthy life expectancies among older adults.

Grecias Macias is a graduate student in the School of Information at the University of Michigan-Ann Arbor. 